\title{
Evaluation of equations for fat-free mass based on anthropometry in infants and young children in South Asia
}

\author{
Bandana Sen ${ }^{1}$, Dilip Mahalanabis ${ }^{1}$, Saijuddin Shaikh ${ }^{1}$, Anura V. Kurpad ${ }^{2}$ and Kaushik Bose ${ }^{3}$ \\ ${ }^{1}$ Society for Applied Studies, CF-198, Salt Lake City, Sector 1, Kolkata 700 064, India \\ ${ }^{2}$ St John's Medical College, Institute of Population Health and Clinical Research, St John's National Academy of Health Sciences, \\ Bangalore 560 034, India \\ ${ }^{3}$ Department of Anthropology, Vidyasagar University, Paschim Midnapore 721 102, India
}

(Received 3 January 2008 - Revised 9 May 2008 - Accepted 29 May 2008 - First published online 30 June 2008)

Rapid postnatal growth in low-birth weight infants increases the risk of hypertension, CHD and type 2 diabetes in adult life. To provide validated tools to study the growth in South Asian infants, we evaluated two published equations to measure total body water (TBW) and fat-free mass (FFM) based on anthropometry in 6- to 24-month-old infants, using ${ }^{2} \mathrm{H}_{2} \mathrm{O}$ dilution. In a method-comparison study in seventy-eight infants aged 6-24 months (forty-two girls and thirty-six boys) from the urban poor attending an immunisation clinic of a hospital in Kolkata, we measured their length to the nearest $0.1 \mathrm{~cm}$, weight to the nearest $10 \mathrm{~g}$ and TBW using ${ }^{2} \mathrm{H}_{2} \mathrm{O}$ dilution. The calculated TBW in $\mathrm{kg}$ (TBWkg) and FFM in $\mathrm{kg}$ (FFMkg) using two equations based on the length and weight were each compared with TBWkg and FFMkg calculated from ${ }^{2} \mathrm{H}_{2} \mathrm{O}$ dilution. The mean FFMkg were 7.31 (SD 1.11), 7.13 (SD 1.08) and 7.26 (SD 1.13) by the ${ }^{2} \mathrm{H}_{2} \mathrm{O}$ dilution method, and the anthropometry equations of Mellits and Cheek (AN-1) and Morgenstern et al. (AN-2), respectively. The mean of the paired difference in FFMkg was 0.18 (SEM 0.06) and 0.04 (SEM 0.07) between ${ }^{2} \mathrm{H}_{2} \mathrm{O}$, and $\mathrm{AN}-1$ and $\mathrm{AN}-2$, respectively. There is a good agreement for FFM derived by $\mathrm{AN}-2$ with ${ }^{2} \mathrm{H}_{2} \mathrm{O}$ dilution. The former is $1 \%$ lower than that obtained from the reference method $(P=0 \cdot 28)$. The AN-2 equation is useful for evaluating FFM in infants in India.

Total body water: Fat-free mass: ${ }^{2} \mathrm{H}_{2} \mathrm{O}$ dilution technique: Infants

Measuring fat-free mass (FFM) in infants and young children is of scientific and public health interest. Recent findings on the relationship between intra-uterine growth retardation and diseases in adults such as hypertension, type 2 diabetes and CHD generated renewed interest in studying the developmental indicators of infants and young children ${ }^{(1-4)}$. Furthermore, it has been shown that more rapid postnatal growth (catch-up growth) in infants born with intra-uterine growth retardation is also a risk factor for these adult diseases ${ }^{(5-8)}$. In South Asian countries, the rate of low birth weight is very high largely due to intra-uterine growth retardation ${ }^{(9)}$. Furthermore, the incidence of hypertension, type 2 diabetes and CHD is higher among South Asians compared with the Caucasians ${ }^{(10)}$. We therefore need population-based studies on growth and its components like FFM in infancy and early childhood. The absence of validated equations for measuring FFM in infants in South Asia based on simple measurements such as height/ length and weight is a known constraint. Are the existing equations suitable for use in infants and young children in South Asia?

In the light of that mentioned earlier, measurement of body composition such as FFM assumes importance. The practical methods for use in clinics and in the field to measure FFM in infants and children are largely based on anthropometry (such as height/length and weight) and equations for children have been developed mainly in developed countries. We found two such validated equations in literature based on anthropometry $^{(11,12)}$ for use in children. Before we can use these equations with confidence on a population different from that on which these equations were developed, it is appropriate to validate them before they are applied on a large scale in infants and children in countries in South Asia. To address this question, we evaluated these two published equations for FFM based on anthropometry. We compared the total body water (TBW) and FFM derived by these equations with a reference method based on isotope dilution using ${ }^{2} \mathrm{H}_{2} \mathrm{O}$.

\section{Subjects and methods}

\section{Subjects}

The present study was conducted in apparently healthy children among the urban poor attending an immunisation clinic of a large charitable government hospital in the city of Kolkata. The hospital service is provided free. The immunisation clinic is held once a week. Each week we interviewed the first four mothers who registered their children

Abbreviations: FFM, fat-free mass; FFMkg, FFM in kg; TBW, total body water; TBWkg, TBW in kg.

* Corresponding author: Dr Dilip Mahalanabis, fax +91 332337 0709, email sas_kolkata@vsnl.net 
in the weekly clinic, and we aimed to recruit up to two children each week. The recruitment was spread over a period of 1 year.

The eligibility criteria for inclusion in the present study were age 6-24 months of either sex, absence of illness during the preceding 1 month, absence of gross congenital anomalies and chronic diseases, and parents' willingness to participate. The socio-economic and demographic features of the families are given in Table 1. These children are from low socio-economic status and records on birth weight and gestation were not available for consideration. Eighty-six children, aged 6-24 months, participated in the present study.

Written informed consent was obtained from the parents and the present study was approved by the ethical review committee of the Society for Applied Studies, Kolkata, India.

\section{Sample size}

Our plan was to evaluate simple prediction equations of measuring FFM for large-scale use, based on anthropometry method. The reference method is based on ${ }^{2} \mathrm{H}_{2} \mathrm{O}$ (a stable isotope) dilution. For an ideal prediction equation, the difference in the measured quantity between the reference method and the method under study should be zero. The sample size will depend on the magnitude of deviation from zero and its CI that will be acceptable for the purpose the method is to be used and therefore can only be indicative. The comparisons will be paired, i.e. the results from the two methods on each subject will be compared. The degree of deviation of the mean of the differences from zero is of interest for the present study. We have calculated the sample size to detect $1.5 \%$ or more deviation from zero difference with a standard deviation of 2. To detect this degree of deviation with $95 \%$ confidence and $90 \%$ power, we need a sample of seventy-one subjects in each group ${ }^{(13)}$. Since the same subject will provide data for FFM by both the reference and the comparison methods, the sample size remains the same, i.e. seventy-one subjects. We added $12 \%$ to this number to give a sample size of eighty subjects.

\section{Anthropometric measurements}

The anthropometric measurements were made using recommended protocols ${ }^{(14,15)}$ and are briefly described. The measurements were taken on the same day the infant underwent ${ }^{2} \mathrm{H}_{2} \mathrm{O}$ dilution test.

Table 1. Socio-economic status of the families

\begin{tabular}{lc}
\hline Variables & Number (\%) \\
\hline House with cement floor, wall and roof & $8(10 \%)$ \\
Lives and cooks in one room & $51(65 \%)$ \\
Family income, £/month (median, quartiles) & $22(18,31)$ \\
Mother's education & \\
Illiterate & $10(13 \%)$ \\
$1-5$ Years of school & $27(35 \%)$ \\
$6-10$ Years of school & $33(42 \%)$ \\
$>10$ Years of school & $8(10 \%)$ \\
\hline
\end{tabular}

\section{Length}

Recumbent length was measured with a wooden measuring board as described earlier ${ }^{(16)}$. The board was made sufficiently broad to cover the shoulder blades. The reading was taken to the nearest $0 \cdot 1 \mathrm{~cm}$.

\section{Weight}

Weight was measured nude, using an electronic platform balance with a precision of $10 \mathrm{~g}$. The balance was checked regularly for accuracy using standard weights.

\section{${ }^{2}$ H-labelled water dilution method}

${ }^{2} \mathrm{H}_{2} \mathrm{O}$, water with a stable isotope of hydrogen, was used. This measurement took place between 09.00 and 14.00 hours. Because of their age, the infants were not fasted. A vast majority of them were breast-fed $(88 \%)$. No food other than breast-feeding was allowed for $3 \mathrm{~h}$ before administrating the ${ }^{2} \mathrm{H}_{2} \mathrm{O}$. Breast-feeding was stopped $1 \mathrm{~h}$ before administrating the ${ }^{2} \mathrm{H}_{2} \mathrm{O}$. As expected, the infants were normally hydrated at the time of the test. Children's baseline saliva was collected by a disposable syringe. We took a measured volume of ${ }^{2} \mathrm{H}_{2} \mathrm{O}$ (99.9\%; Sigma, St Louis, MO) approximately equivalent to $50 \mathrm{mg} / \mathrm{kg}$ body weight in a disposable container. ${ }^{2} \mathrm{H}_{2} \mathrm{O}$ has a specific gravity of $1 \cdot 107$. We then weighed the ${ }^{2} \mathrm{H}_{2} \mathrm{O}$ dose using a precision balance and the weight with an accuracy of $0 \cdot 1 \mathrm{mg}$ was recorded and used in calculating TBW. It was mixed with $20 \mathrm{ml}$ of distilled water and the child drank it from a disposable syringe. The empty container was rinsed with two consecutive lots of $15 \mathrm{ml}$ of distilled water and the child drank both lots from the same disposable syringe. Time was allowed to equilibrate the ${ }^{2} \mathrm{H}_{2} \mathrm{O}$ into the body fluid. No food or fluid including breast milk and water was permitted during the equilibration period of $3 \mathrm{~h}$. At the end of the equilibration period, the second sample of saliva was collected and analysed for ${ }^{2} \mathrm{H}$ using a dual-inlet mass spectrometer (Europe Scientific, Crewe, $\mathrm{UK}$ ), using the zinc reduction technique. The results of ${ }^{2} \mathrm{H}_{2} \mathrm{O}$ concentration in the saliva samples were used for calculating the TBW.

The following equation was used:

$\mathrm{TBW}$ in $\mathrm{kg}=(\mathrm{TBW}$ in moles $\times$ molecular weight

$$
\text { of } \mathrm{H}_{2} \mathrm{O} \text { (i.e. 18.0153))/1000. }
$$

TBW in moles was calculated as follows:

$$
\text { TBW in moles }=\left(F_{1} \times N_{1}\right) \div\left(F_{2} \times 1 \cdot 041\right) \text {, }
$$

where $F_{1}=$ (concentration of ${ }^{2} \mathrm{H}_{2} \mathrm{O}$ in atom per cent (i.e. $\left.99.9) \times 10^{6} / 100-150\right)$ ppm of ${ }^{2} \mathrm{H}_{2} \mathrm{O}, F_{2}=$ ppm after dose ppm before dose of ${ }^{2} \mathrm{H}_{2} \mathrm{O}$ (using concentrations in saliva samples) and $N_{1}=$ dose of ${ }^{2} \mathrm{H}_{2} \mathrm{O}$ in gram/molecular weight of ${ }^{2} \mathrm{H}_{2} \mathrm{O}$ (i.e. 20-0274).

In using ${ }^{2} \mathrm{H}$ for estimating $\mathrm{TBW}$, it should be noted that this isotope undergoes some exchange with non-aqueous hydrogen and a correction factor of 1.041 was used. The FFM was calculated as TBW divided by an age- and sex-specific hydration factor for $\mathrm{FFM}^{(17)}$. 


\section{Anthropometry-based published equations}

The prediction equations for TBW using weight and length that we evaluated in the present study are given later.

Anthropometry-based equation $\mathrm{AN}-1^{(11)}$ :

$$
\begin{gathered}
\text { For boys: } \mathrm{TBW}(\mathrm{kg})=-1.927+0.465 W+0 \cdot 045 H . \\
\text { For girls: } \mathrm{TBW}(\mathrm{kg})=0.076+0.507 W+0.013 H,
\end{gathered}
$$

where $H=$ length in $\mathrm{cm}, W=$ weight in $\mathrm{kg}$ and when $H \leq 132.7 \mathrm{~cm}$ for boys and $H \leq 110.8 \mathrm{~cm}$ for girls. These equations were derived from studies on the US subjects aged 1-34 years.

Anthropometry-based equation $\mathrm{AN}-2^{(12)}$ :

$$
\begin{aligned}
& \text { For boys: TBW }(\mathrm{kg})=0.0846 \times(H \times W)^{0.65} \text {. } \\
& \text { For girls: TBW }(\mathrm{kg})=0.0846 \times 0.95 \times(H \times W)^{0.65} \text {. }
\end{aligned}
$$

These equations were derived from studies on the US subjects aged 3 months to 13 years.

The same hydration factors for $\mathrm{FFM}^{(17)}$ were used for calculating FFM from TBW derived by the anthropometrybased equations and ${ }^{2} \mathrm{H}_{2} \mathrm{O}$ dilution technique.

\section{Statistical analysis}

Epi Info version 6.0 $0^{(18)}$ and Stata version 7.0 $0^{(19)}$ were used for data entry and statistical analysis. For anthropometric data, a software package based on National Center for Health Statistics database as provided with the Epi Info software was used. As is conventionally done, correlation and regression analysis were used to compare the TBW based on anthropometry with the reference method, i.e. ${ }^{2} \mathrm{H}_{2} \mathrm{O}$ dilution technique. We plotted the results along the 'line of equality' (i.e. the line at a $45^{\circ}$ angle) to visually examine the concordance ${ }^{(20)}$.
Furthermore, the difference in TBW for each subject between each of the two anthropometry equations and ${ }^{2} \mathrm{H}_{2} \mathrm{O}$ dilution (paired data) was evaluated for their difference from zero by $t$-test. Mean (SD 2) was calculated to derive the range within which $95 \%$ of the values were expected to $\operatorname{lie}^{(20)}$.

\section{Results}

Eighty-six children participated in the present study. In eight of them, the ${ }^{2} \mathrm{H}_{2} \mathrm{O}$ procedures were incomplete because of vomiting or being fed during the equilibration period. They were dropped from the study. The study infants were predominantly breast-fed $(88 \%)$. Characteristics of the study children are shown in Table 2. Weight-for-age, length-for-age and weight-for-length standard deviation scores suggest some degree of underweight, wasting and stunting. Using the two equations, i.e. $\mathrm{AN}-1^{(11)}, \mathrm{AN}-2^{(12)}$, and by ${ }^{2} \mathrm{H}_{2} \mathrm{O}$ dilution, we derived TBW in $\mathrm{kg}$ (TBWkg). Mean TBW based on AN-1 was $1.86 \%$ lower than the reference method $(P=0.002)$ and TBW derived by AN-2 was $0.75 \%$ lower than the reference method $(P=0 \cdot 2)$. Calculated TBW and FFM using ${ }^{2} \mathrm{H}_{2} \mathrm{O}$ dilution technique and the two anthropometry equations are shown in Table 3. Mean FFM derived by AN-1 was $2.30 \%$ lower than the reference method $(P=0.002)$ and FFM derived by $\mathrm{AN}-2$ was $0.79 \%$ lower than ${ }^{2} \mathrm{H}_{2} \mathrm{O}$ dilution $(P=0.29)$. As expected, the mean FFM in boys tended to be higher than that in the girls for all the three methods. The differences however did not reach statistical significance. The mean, SD values of the difference in FFM in $\mathrm{kg}$ (FFMkg) and percentage of body weight between those derived by ${ }^{2} \mathrm{H}_{2} \mathrm{O}$ dilution and each of the two equations under study and $95 \%$ CI of the difference are shown in Table 4. The results show that the FFMkg derived

\begin{tabular}{|c|c|c|c|c|}
\hline \multirow[b]{2}{*}{ Characters } & \multicolumn{2}{|c|}{ Boys ( $n$ 36) } & \multicolumn{2}{|c|}{ Girls ( $n$ 42) } \\
\hline & Mean or number & SD & Mean or number & SD \\
\hline Age, months (range) & $15 \cdot 3(6 \cdot 2-23 \cdot 8)$ & $5 \cdot 6$ & $16 \cdot 2(7-23 \cdot 6)$ & $5 \cdot 3$ \\
\hline$<12$ months & 13 & & 10 & \\
\hline$\geq 12$ months & 23 & & 32 & \\
\hline Body weight, kg (range) & $8.9(6.4-12.1)$ & 1.3 & $8.8(6.2-11.9)$ & 1.4 \\
\hline Length, $\mathrm{cm}$ (range) & $76.6(65.5-86.5)$ & $6 \cdot 0$ & $76.0(63.8-86.0)$ & $6 \cdot 1$ \\
\hline $\mathrm{WHZ}^{*}$ & -1.37 & 1.05 & -1.01 & 0.70 \\
\hline $\mathrm{WHZ}<-2$ & 10 & & 3 & \\
\hline$W H Z \geq-2$ and $<-1$ & 14 & & 17 & \\
\hline$W H Z \geq-1$ & 12 & & 22 & \\
\hline WAZ* & -1.57 & $1 \cdot 10$ & -1.33 & 0.95 \\
\hline$W A Z<-2$ & 12 & & 10 & \\
\hline$W A Z \geq-2$ and $<-1$ & 16 & & 18 & \\
\hline$W A Z \geq-1$ & 8 & & 14 & \\
\hline$H A Z^{*}$ & -0.87 & 1.05 & -0.87 & $1 \cdot 22$ \\
\hline$H A Z<-2$ & 4 & & 7 & \\
\hline $\mathrm{HAZ} \geq-2$ and $<-1$ & 10 & & 13 & \\
\hline$H A Z \geq-1$ & 22 & & 22 & \\
\hline Mid-arm circumference (range) & $14 \cdot 1(12 \cdot 0-16 \cdot 5)$ & 1.1 & $13.9(12.5-16.0)$ & 0.9 \\
\hline Biceps (range) & $3 \cdot 3(2 \cdot 0-6 \cdot 0)$ & 0.9 & $3.4(2 \cdot 0-5 \cdot 8)$ & 0.7 \\
\hline Triceps (range) & $5.4(3.2-9.0)$ & 1.3 & $5.6(4.0-8.0)$ & 0.9 \\
\hline Subscapular (range) & $6.2(4.0-10 \cdot 0)$ & 1.3 & $6.0(4.0-10 \cdot 0)$ & $1 \cdot 2$ \\
\hline Suprailiac (range) & $4.8(2.5-8.0)$ & $1 \cdot 1$ & $4.6(3.0-7.0)$ & 1.0 \\
\hline
\end{tabular}
by the equation $\mathrm{AN}-2^{(12)}$ gives a better agreement with the reference method; $95 \%$ limits of agreement with the reference

Table 2. Characteristics of subjects

${ }^{*}$ WHZ, WAZ and HAZ are weight-for-height, weight-for-age and height-for-age standard deviation scores, respectively, compared with National Center for Health Statistics reference. 
Table 4. Mean, SD of the difference in FFM (of paired values) in $\mathrm{kg}$ and percentage of body weight between those derived by ${ }^{2} \mathrm{H}$-labelled water dilution and by each of the two equations under study and $95 \% \mathrm{Cl}$ of the difference

\begin{tabular}{|c|c|c|c|c|}
\hline & $\begin{array}{l}\text { Mean } \\
\text { difference } \\
\text { in } \mathrm{kg} \text { (as \% } \\
\text { body weight) }\end{array}$ & SD & $95 \% \mathrm{Cl}$ & $P^{*}$ \\
\hline${ }^{2} \mathrm{H}_{2} \mathrm{O}-\mathrm{AN}-1^{\mathrm{a}}$ & $0.18(2.30)$ & $\begin{array}{c}0.57 \\
(6.39)\end{array}$ & $\begin{array}{c}0.05,0.31 \\
(0.86,3.74)\end{array}$ & $\begin{array}{c}0.007 \\
(0.002)\end{array}$ \\
\hline${ }^{2} \mathrm{H}_{2} \mathrm{O}-\mathrm{AN}-2^{\mathrm{b}}$ & $0.04(0.79)$ & $\begin{array}{c}0.57 \\
(6.51)\end{array}$ & $\begin{array}{l}-0.09,0.17 \\
(-0.67,2.26)\end{array}$ & $\begin{array}{c}0.505 \\
(0.285)\end{array}$ \\
\hline
\end{tabular}

FFM; fat-free mass

${ }^{\text {a }}$ Difference between ${ }^{2} \mathrm{H}_{2} \mathrm{O}$ and anthropometry methods (AN-1).

${ }^{b}$ Difference between ${ }^{2} \mathrm{H}_{2} \mathrm{O}$ and anthropometry methods (AN-2).

* The $t$ test evaluates the difference in the paired values from zero.

method (i.e. mean (SD 2)) were -0.96 to 1.32 and $-1 \cdot 10$ to $1 \cdot 18$ for $\mathrm{AN}-1$ and $\mathrm{AN}-2$, respectively. Distribution of points for TBWkg along the line of identity between ${ }^{2} \mathrm{H}_{2} \mathrm{O}$ and $\mathrm{AN}-1$ and ${ }^{2} \mathrm{H}_{2} \mathrm{O}$ and $\mathrm{AN}-2$ methods is shown in Fig. 1 (a,b). Similarly, FFMkg are plotted in Fig. 2 (a,b). Bland-Altman plots of the differences in TBWkg in each participant between ${ }^{2} \mathrm{H}_{2} \mathrm{O}$ and AN-1 and ${ }^{2} \mathrm{H}_{2} \mathrm{O}$ and AN-2 methods against average TBWkg are shown in Fig. 1 (c,d); mean differences were 0.15 and 0.05, respectively. Similarly, for FFMkg, the differences are plotted in Fig. 2 (c,d); mean differences were 0.18 and $0 \cdot 04$, respectively. In Fig. 3, individual data points for percentage of FFM derived by the two anthropometry equations and by the reference method are plotted against age in months. Age- and sex-specific reference percentage of FFM in healthy American infants derived by multicomponent models ${ }^{(17)}$ are also plotted for comparison. The percentage of FFM in the study infants derived by all three methods are consistently higher than the reference values in the US infants, indicating that the infants under study are considerably leaner and have lower fat mass percentage.

\section{Discussion}

The weight-for-height indices such as Z-scores have not been evaluated for their ability to predict FFM. Weight-for-height indices and recently introduced BMI Z-score for children do not distinguish fat and lean masses. In fact there is a 2-fold range of variation in fatness for a given BMI value in individual children ${ }^{(21)}$. Based on skin-fold measurement, Yajnik and colleagues $^{(10,22)}$ have shown that Indian babies are not only small at birth but they also have less muscle mass and relatively more fat mass, the so-called 'thin-fat baby' syndrome. They further showed that thin-fat babies grow up to become thin-fat adults with thinner limbs and high waist-hip ratio; they appear to be fetally programmed and predisposed to diabetes. They also showed that the smallness and thinness of the Indian babies is present at birth and an unusual thinfat body composition is associated with the insulin-resistance syndrome $^{(10,23)}$. To further understand and study such phenomena, validated prediction equations for FFM based on anthropometry should be of value. The conventional weightfor-height indices and BMI percentile are likely to be inadequate to understand the growth and development of FFM.

The purpose of the present study was to evaluate predictive equations for the percentage of FFM derived from TBW by 

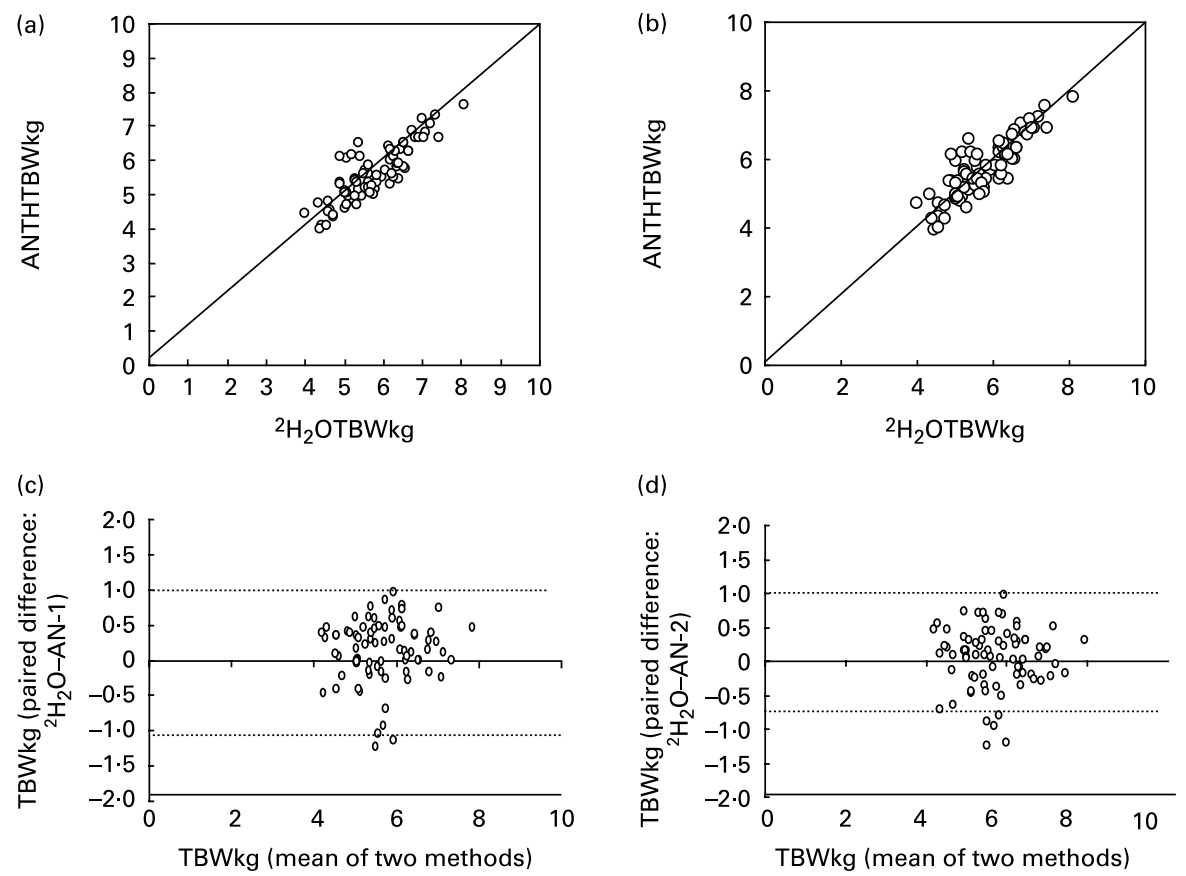

Fig. 1. (a,b) TBWkg: Individual data points comparing values derived by the reference method $\left({ }^{2} \mathrm{H}\right.$-labelled water dilution) with each of the anthropometric equations under study are plotted along the 'line of identity' (at $45^{\circ}$ angle). ANTHTBWkg: TBWkg derived by the two equations based on anthropometry (AN-1 and AN-2), plotted against ${ }^{2} \mathrm{H}_{2} \mathrm{O}$ method $\left(R^{2}=0.73\right.$ and 0.74 , respectively). ${ }^{2} \mathrm{H}_{2} \mathrm{OTBWkg:}$ TBWkg derived by ${ }^{2} \mathrm{H}$-labelled water dilution method ${ }^{(11,12)}$. (c,d) Bland-Altman plots of the difference (mean (SD 2)) in each participant between TBWkg derived by ${ }^{2} \mathrm{H}$-labelled water reference method and each of the methods under study plotted against average of the TBWkg by ${ }^{2} \mathrm{H}$-labelled water method and each of the study methods ${ }^{(11,12)}$. ${ }^{2} \mathrm{H}$-labelled water-AN-1: mean difference $=0.15, \mathrm{SD}=0.44, P=0.005,{ }^{2} \mathrm{H}$-labelled water-AN-2: mean difference $=0.05, \mathrm{SD}=0.45, P=0.372$.
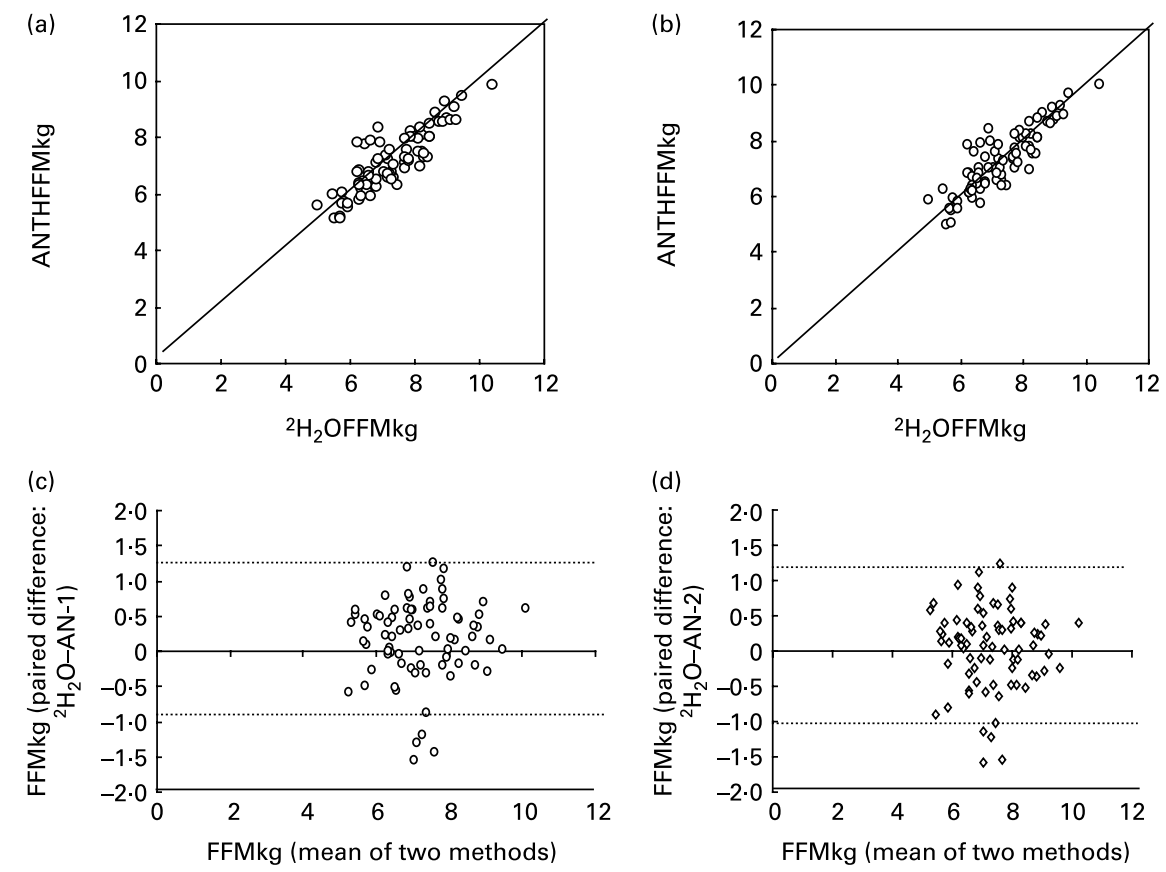

Fig. 2. (a,b) FFMkg: Individual data points comparing values derived by the reference method $\left({ }^{2} \mathrm{H}\right.$-labelled water dilution) with those by the two equations under study are plotted along the 'line of identity' (at $45^{\circ}$ angle). ANTHFFMkg: FFMkg derived by the two equations based on anthropometry (AN-1 and AN-2), plotted against ${ }^{2} \mathrm{H}$-labelled water method $\left(R^{2}=0.75\right.$ and 0.76 , respectively). ${ }^{2} \mathrm{H}_{2} \mathrm{OFFM} \mathrm{kg:} \mathrm{FFMkg} \mathrm{derived} \mathrm{by}{ }^{2} \mathrm{H}$-labelled water dilution method ${ }^{(11,12)}$. (c,d) Bland-Altman plots of the difference (mean (SD 2)) in each participant between FFMkg derived by ${ }^{2} \mathrm{H}$-labelled water as the reference method and each of the methods under study plotted against average of the FFMkg by ${ }^{2} \mathrm{H}$-labelled water method and each of the study methods ${ }^{(11,12)}$. ${ }^{2} \mathrm{H}$-labelled water-AN-1: mean difference $=0 \cdot 18$, $\mathrm{SD}=0.57, P=0.007,{ }^{2} \mathrm{H}$-labelled water-AN-2: mean difference $=0.04, \mathrm{SD}=0.57, P=0.505$. 

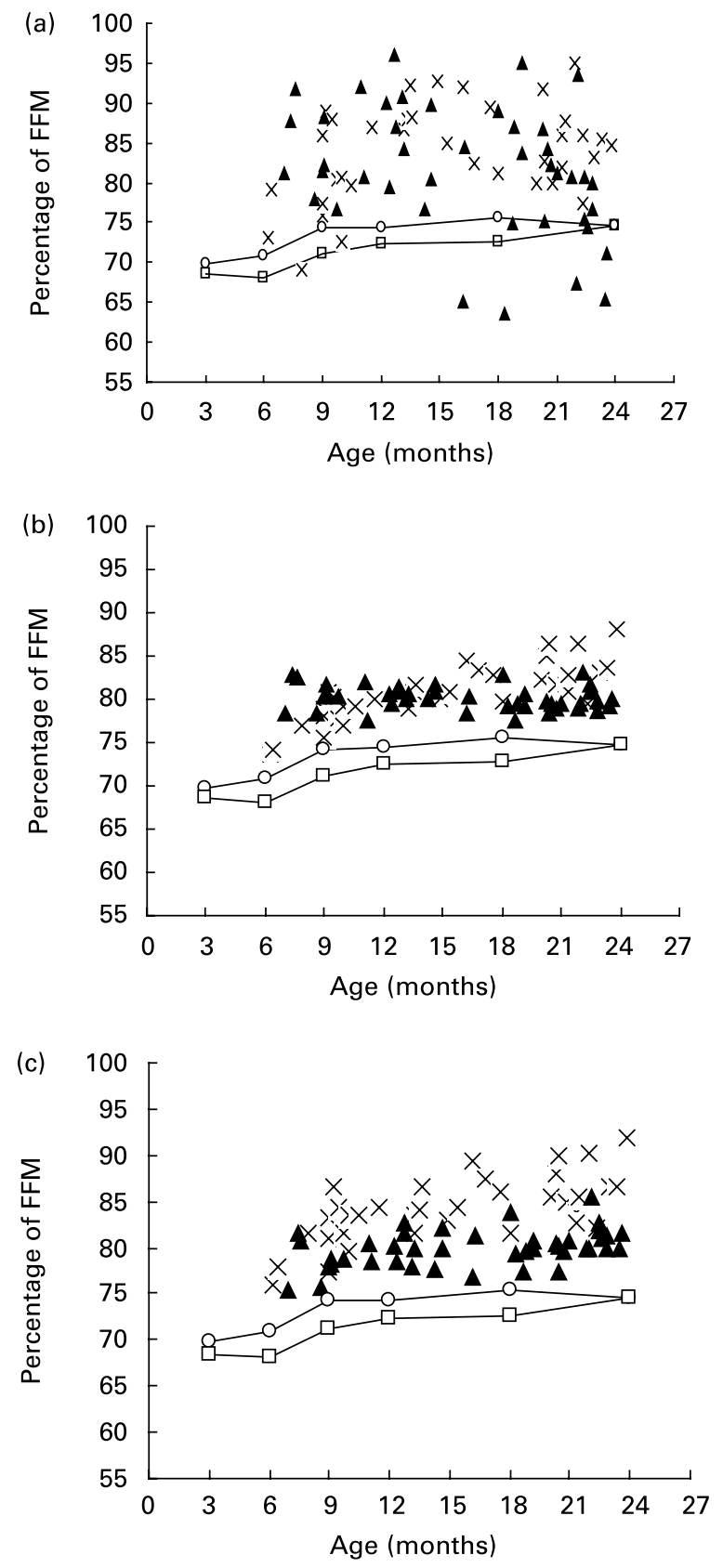

Fig. 3. Individual data points for percentage of FFM derived by (a) ${ }^{2} \mathrm{H}$-labelled water dilution method and (b,c) the two anthropometry equations ${ }^{(11,12)}$ are plotted against age in months. Age- and sex-specific reference percentage of FFM in healthy American infants derived by multicomponent models ${ }^{(17)}$ are plotted for comparison (data points are connected). Boys $(X)$, girls $(\boldsymbol{\Delta})$, boys (-O-, Butte $\left.{ }^{(17)}\right)$, girls $\left(-\square-\right.$, Butte $\left.{ }^{(17)}\right)$.

the anthropometry method for use on South Asian infants and young children. We found two equations in the literature for measuring TBW based on anthropometry of infants and children aged 6-24 months. Comparing these two equations with the reference method, we note that the TBW by $\mathrm{AN}-2^{(12)}$ gave better agreement than the one by $\mathrm{AN}-1^{(11)}$. The study to develop $\mathrm{AN}-2^{(12)}$ used a larger sample and includes data from several studies including those of Mellits and $\mathrm{Cheek}^{(11)}$. However, due to relatively wide limits of agreement (i.e. large SD) with the reference method, the equation is less useful for individual infants. However, given that the mean difference of the paired values of FFM is nearly zero and the $95 \% \mathrm{CI}$ is within a narrow range, the method of Morgenstern et al. should be eminently suitable for comparing groups. Butte et al. ${ }^{(17)}$ have recently provided reference data on the body composition of children aged 0.5-24 months from the USA. Fig. 3 shows that the percentage of FFM is consistently higher in the study infants compared with those in the USA. This is so, by both the anthropometry and reference methods based on ${ }^{2} \mathrm{H}_{2} \mathrm{O}$ dilution. These findings are consistent with the degree of undernutrition present in these infants (Table 2).

Some comment on the prediction equations we have evaluated is pertinent. Widely used anthropometry equations developed by Mellits \& Cheek were derived on children with a wide age range of 3 months to 9 years (estimated). Their data include twenty-three boys and nine girls under 1 year of age. Morgenstern et al. used data on 167 children of a wide age range of 3 months to 13 years derived from several studies and included the data of Mellits \& Cheek and it appears from the data plots that they have had a reasonable number under 2 years of age (though not stated).

Techniques for validation such as underwater weighing are not feasible in infants and young children. Use of the methods that involve any degree of radiation (e.g. dual-energy X-ray absorptiometry, radioactive tracers) is also not desirable for infants. We therefore used a stable isotope dilution technique as the reference standard. Variation exists among laboratories in the way TBW is calculated from ${ }^{2} \mathrm{H}_{2} \mathrm{O}$ dilution measurements. One of us (S. S.) has had the opportunity to review the isotope dilution methods with Dr Tom Preston of the Stable Isotope Biochemistry Laboratory of the Scottish Universities Environmental Research Centre, and based on this consultation, we used a unified approach for calculating TBW using ${ }^{2} \mathrm{H}_{2} \mathrm{O}$ dilution as described by Schoeller \& Jones ${ }^{(24)}$. Isotope dilution methods use a two-component model to measure FFM and fat mass and are generally safe, reliable, accurate and feasible in infants and children. To derive FFM, one has to use age- and sex-specific hydration factors derived by multicomponent models ${ }^{(17,25)}$. While the hydration of FFM changes with age and maturation, use of age- and sex-specific hydration factor largely minimises errors associated with maturation. This however may not be true in some clinical situations such as dialysis patients. For this age group, the hydration factor for FFM ranged from 80.7 to 77.0 for boys and 80.7 to 78.0 for girls ${ }^{(17)}$. The hydration factors for FFM proposed earlier for 1- to 5-yearold children give closely similar results ${ }^{(25,26)}$. Measurement of TBW using ${ }^{2} \mathrm{H}_{2} \mathrm{O}$ dilution methods has been used as a reference method in many of the classic studies of body composition in children ${ }^{(27-30)}$.

Recently, Tennefors \& Forsum have evaluated the usefulness of measuring body fatness derived from skin-fold thickness and BMI using TBW by ${ }^{2} \mathrm{H}_{2} \mathrm{O}$ dilution as the reference method. Both these approaches were found to be inadequate in placing 9- and 14-month-old children in the correct body fatness group. It may be noted that TBW is better used to measure FFM, and evaluation of fatness by this method is indirect ${ }^{31}$.

To conclude, among the presently available prediction equations based on anthropometry for measuring FFM in infants and young children, the one by Morgenstern and colleagues 
is suitable for studying infants in India for prospective cohort studies and intervention studies such as the impact of breastfeeding programmes on chronic illness in later life ${ }^{(32)}$.

\section{Acknowledgements}

We thank Md Jakir Hossain for statistical assistance. We thank Dr Sumita Jana, R. M. O. of ID \& B. G. Hospital, and nursing staff of this hospital for their support and assistance in the conduct of the present study. The study was supported by the Society for Applied Studies Trust. B. S., a research fellow, carried out the study procedures, and took part in the analysis and in preparing the manuscript. D. M. conceived the study design and experiment, trained B. S. in anthropometry and ${ }^{2} \mathrm{H}_{2} \mathrm{O}$ dilution test and statistical analysis, supervised her work and took part in data analysis and interpretation and in preparing the manuscript. S. S. assisted B. S. in the standardisation of procedures for anthropometry and ${ }^{2} \mathrm{H}_{2} \mathrm{O}$ dilution. He also took part in the study design, analysis and interpretation of the findings. A. V. K. carried out the ${ }^{2} \mathrm{H}_{2} \mathrm{O}$ analysis in the laboratory, took part in the interpretation of the findings and in critically reviewing the manuscript. K. B. took part in the study design, secondary supervision, interpretation and preparing the manuscript. Authors do not have any conflict of interest to declare.

\section{References}

1. Barker DJ (1995) Fetal origins of coronary heart disease. Br Med $J$ 311, 171-174.

2. Eriksson JG, Forsen T, Tuomilehto J, Osmond C \& Barker DJ (2003) Early adiposity rebound in childhood and risk of type2 diabetes in adult life. Diabetologia 46, 190-194.

3. Barker DJ (2001) A new model for the origins of chronic disease. Med Health Care Philos 4, 31-35.

4. Barker DJ (1999) The long-term outcome of retarded fetal growth. Schweiz Med Wochenschr 129, 189-196.

5. Barker DJ, Gluckman PD, Godfrey KM, Harding JE, Owens JA \& Robinson JS (1993) Fetal nutrition and cardiovascular disease in adult life. Lancet 341, 938-941.

6. Eriksson JG, Forsen T, Tuomilehto J, Winter PD, Osmond C \& Barker DJ (1999) Catch-up growth in childhood and death from coronary heart disease: longitudinal study. BrMed J318, 427-431.

7. Lucas A (1991) Programming by early nutrition in man; Ciba Found Symp 156, 38-50; discussion 50-55.

8. Singhal A \& Lucas A (2004) Early origins of cardiovascular disease: is there a unifying hypothesis? Lancet 363, 1642-1645.

9. de Onis M, Blossner M \& Villar J (1998) Levels and pattern of intrauterine growth retardation in developing countries. Eur $J$ Clin Nutr 52, Suppl. 1, S5-S15.

10. Yajnik CS, Lubree HG, Rege SS, Naik SS, Deshpande JA, Deshpande SS, Joglekar CV \& Yudkin JS (2002) Adiposity and hyperinsulinemia in Indians are present at birth. $J$ Clin Endocrinol Metab 87, 5575-5580.

11. Mellits ED \& Cheek DB (1970) The assessment of body water and fatness from infancy to adulthood. Monogr Soc Res Child Dev 35, 12-26.

12. Morgenstern BZ, Mahoney DW \& Warady BA (2002) Estimating total body water in children on the basis of height and weight: a reevaluation of the formulas of Mellits \& Cheek. J Am Soc Nephrol 13, 1884-1888.

13. Pocock SJ (1999) Clinical Trials: A Practical Approach, pp. 123-138. New York: John Wiley \& Sons.

14. Lohman TG, Roche AF \& Martorell R (editors) (1988). Anthropometric Standarization Reference Manual, pp. 55-70. Champaign, IL: Human Kinetic Books.

15. Cameron N (2004) Measuring growth. In Methods in Human Growth Research, pp. 68-107 [R Hauspie, N Cameron and L Molinari, editors]. Cambridge: Cambridge University Press.

16. Shaikh S, Mahalanabis D, Kurpad AV \& Khaled MA (2002) Validation of an anthropometric equation and bioelectrical impedance analysis (BIA) technique to measure body composition of children in India using $\mathrm{D}_{2} \mathrm{O}$ dilution method. Nutr Res 22, 685-694.

17. Butte NF, Hopkinson JM, Wong WW, Smith EO \& Ellis KJ (2000) Body composition during the first 2 years of life: an updated reference. Pediatr Res 47, 578-585.

18. Epi Info version 6 (1994) A Word Processing, Database, and Statistics Program for Epidemiology on Microcomputers. Atlanta, GA: Centers for Disease Control and Prevention.

19. Stata version 7, (1985-2001) Stata Corporation, Stata Press, 4905 Lakeway Drive, College Station, TX 77845, USA

20. Bland JM \& Altman DG (1986) Statistical methods for assessing agreement between two methods of clinical measurement. Lancet i, 307-310.

21. Wells JC \& Fewtrell MS (2006) Measuring body composition Arch Dis Child 91, 612-617.

22. Yajnik CS, Fall CH, Coyaji KJ, Hirve SS, Rao S, Barker DJ, Joglekar C \& Kellingray S (2003) Neonatal anthropometry: the thin-fat Indian baby. The Pune Maternal Nutrition Study. Int J Obes Relat Metab Disord 27, 173-180.

23. Yajnik CS (2004) Early life origins of insulin resistance and type 2 diabetes in India and other Asian countries. J Nutr 134, 205-210.

24. Schoeller DA \& Jones PJH (1987) Measurement of total body water by isotope dilution: a unified approach to calculations. In In Vivo Body Composition Studies, pp. 131-137 [KJ Ellis, S Yasumura and WD Morgan, editors]. London: Inst. Phys. Sci. Med.

25. Ziegler EE, O'Donnell AM, Nelson SE \& Fomon SJ (1976) Body composition of the reference fetus. Growth 40, 329-341.

26. Fomon SJ, Haschke F, Ziegler EE \& Nelson SE (1982) Body composition of reference children from birth to age 10 years. Am J Clin Nutr 35, 1169-1175.

27. Fomon SJ, Haschke F, Ziegler EE \& Nelson SE (1982) Body composition of reference children from birth to age 10 years. Am J Clin Nutr 35, 1169-1175.

28. Wells JC, Fuller NJ, Dewit O, Fewtrell MS, Elia M \& Cole TJ (1999) Four-component model of body composition in children: density and hydration of fat-free mass and comparison with simpler models. Am J Clin Nutr 69, 904-912.

29. Forbes G (1987) Human Body Composition: Growth Aging, Nutrition and Activity. New York: Springer.

30. Fomon SJ \& Nelson SE (2002) Body composition of the male and female reference infants. Annu Rev Nutr 22, 1-17.

31. Tennefors $C$ \& Forsum E (2004) Assessment of body fatness in young children using the skinfold technique and BMI $v$. body water dilution. Eur J Clin Nutr 58, 541-547.

32. Lucas A \& Sampson HA (2006) Primary prevention by nutrition intervention in infancy and childhood. Nestle Nutr Workshop Ser Pediatr Program 57, 1-273. 